\title{
In-situ Survey of an Unstructured Block Ramp
}

\author{
Ralph EIKENBERG ${ }^{\bowtie}$ and Jochen ABERLE \\ Leichtweiß-Institute for Hydraulic Engineering and Water Resources, \\ Division of Hydraulic Engineering and River Morphology, Technische Universität Braunschweig, \\ Braunschweig, Germany \\ $\checkmark$ r.eikenberg@tu-braunschweig.de
}

\begin{abstract}
This paper describes the in-situ survey of an unstructured block ramp to obtain a detailed topographical digital model for a research project focusing on the fish-based identification of migration corridors. The strategy to drain the block ramp in the field for the survey is described and the obtained digital model is presented. The digital model will be used in subsequent experiments with live fish in the field and laboratory to link fish trajectories, the local flow field, and the bed topography to improve the development of new and enhanced design criteria for nature-like unstructured block ramps.
\end{abstract}

Keywords: unstructured block ramps, structure from motion photogrammetry, terrestrial laser scan, ecohydraulics.

\section{INTRODUCTION AND PROJECT OVERVIEW}

Unstructured block ramps are nature-based hydraulic structures which are built in rivers for the restoration of the ecological connectivity. They are characterized by a spatially heterogeneous roughness structure and flow conditions due to the irregular arrangement of large stones and boulders. Compared to more geometrically defined structures with cross bars or regularly arranged boulders, unstructured ramps fit well into the appearance of the river landscape and provide additional habitat for the aquatic flora and fauna. Until today, the hydraulic design of these structures is based on empirical approaches considering only reach-averaged values of water depths and flow velocities. This means that local hydrodynamic flow conditions, which are important for fish passage, cannot be adequately quantified. It is therefore not possible to guarantee the existence of functioning migration corridors for fish, and this is why this type of block ramp is often not implemented despite its advantages. 
The project MigRamp aims at identifying and quantifying migration corridors of ascending fish on such nature-based hydraulic structures by linking fish trajectories to bed topography and the local flow field. For this purpose, combined fish-biological and hydraulic studies will be carried out in cooperation with the river maintenance association Leineverband and Vattenfall Research and Development AB (Vattenfall R\&D). The corresponding studies will be carried out on an existing nature-like unstructured block ramp in the river Ilme in Lower Saxony, Germany, and on a 1:1 partial model of this ramp in the "Laxelerator", a unique research facility for ethohydraulic experiments in the Vattenfall hydraulic engineering laboratory in Älvkarleby, Sweden. The purpose of this paper is to describe the topographical in-situ survey of the block ramp that was carried out in October 2020.

\section{RAMP SCAN}

The unstructured block ramp in the Ilme river, which is in the focus of MigRamp, was built after a weir removal to conduct water to a diverted historical mill channel (Fig. 1a). For the survey by structure-from-motion (SfM) photogrammetry and terrestrial laser scanning (TLS), it was necessary to drain the ramp for a few hours. Before starting the temporary construction works for diverting the flow (approx. $700 \mathrm{l} / \mathrm{s}$ on that day), the fish in the ramp area were professionally recovered by means of electrofishing and relocated upstream. The diversion of the water was achieved by constructing a temporary dam using gravel-filled big bags. The dam was additionally sealed with a plastic sheet and sandbags and seepage water was intercepted by pumps and fed back into the Ilme downstream of the ramp structure (Fig. 1b). A further pump installed upstream of the temporary dam provided a sufficient environmental flow (approx. $150 \mathrm{l} / \mathrm{s}$ ) for the duration of the survey, so that the river did not run dry downstream of the ramp.

A total of 16 marker points were distributed on the drained ramp for SfM together with five fixed points for later measurements. The corresponding coordinates were recorded using differential GPS. Four photo sets were created with different cameras to ensure high data quality for SfM, and the ramp surface was additionally surveyed by TLS. After completion of the work, the dam was removed, and the original condition of the ramp was restored. The final result of the in-situ survey, in which about 15 people from different institutions were involved, was a GPS referenced point cloud ( $~ 85$ million points on $\sim 90 \mathrm{~m}^{2}$ projected area) which will serve as the basis for a 1:1 partial model of the ramp in the "Laxelerator" (Fig. 1c).

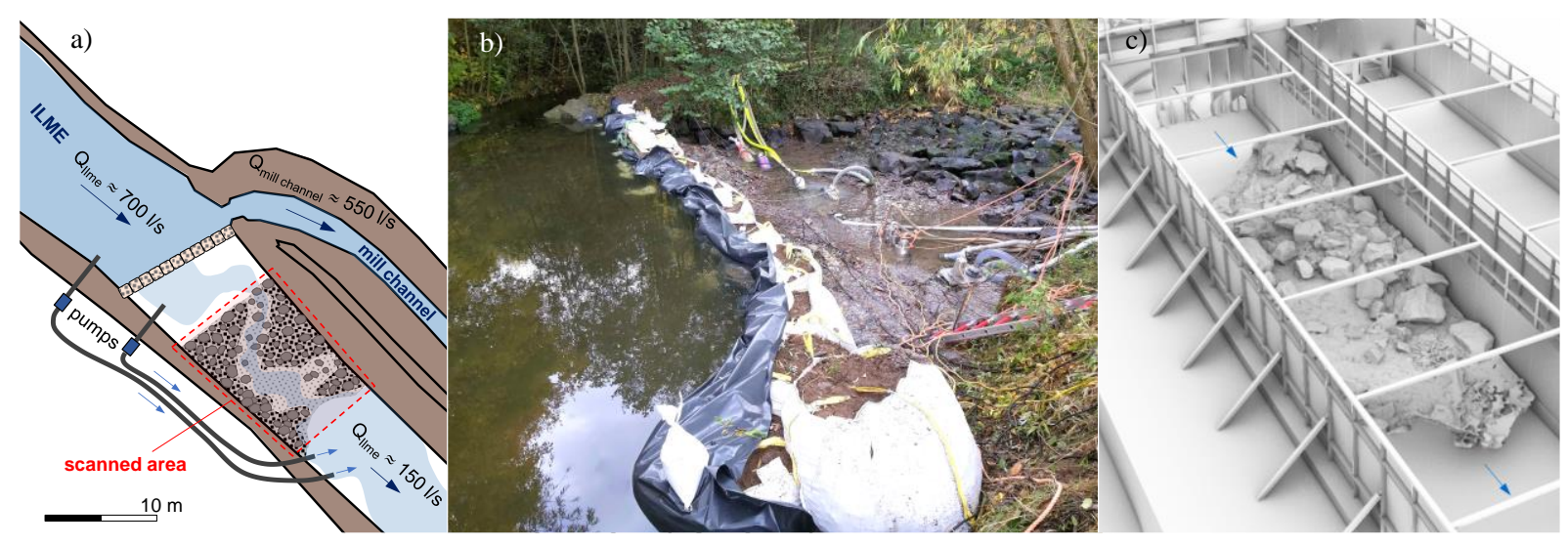

Fig. 1: a) top view sketch of the water damming and diversion, b) dam and drained ramp, c) concept sketch for the 1:1 partial model in the "Laxelerator", based on a 3d mesh of the existing ramp. 
Acknowledgments. We acknowledge the support of the Leineverband (Northeim, Germany) and everyone who contributed to the success of the ramp scan from TU Braunschweig, Federal Agency for Technical Relief (OV Einbeck), and the Fischereiverein Einbeck e.V. The MigRamp project is funded by the Deutsche Bundesstiftung Umwelt (DBU), Germany.

Received 22 March 2021

Accepted 12 April 2021 